\title{
KANT E A MENTIRA
}

\author{
Francisco Eliandro Souza do Nascimento ${ }^{1}$ \\ Universidade Estadual do Ceará (UECE) \\ D https://orcid.org/0000-0003-1617-6134 \\ Jorge Luis Carneiro Lopes ${ }^{2}$ \\ Universidade Estadual do Ceará (UECE)
}

\section{RESUMO:}

Neste artigo abordaremos a questão da mentira, em Kant, vinculando a questões de ordem moral. Pois, sendo a ética e o direito ramos da moral, o problema da mentira encontra-se em saber se ela é uma questão ética ou jurídica, ou se é um problema moral, que engloba tanto a ética como o direito, que não legitimam tal ato. Iniciaremos esta unidade com a análise dos conceitos de moral, ética e direito buscando compreender o que constitui cada um desses campos da cultura e qual a distinção entre ambos. Em seguida trataremos, em especial, da questão da mentira na filosofia prática de Kant, abordando o seu posicionamento ético sobre o ato de mentir, onde é levantada a questão em saber se uma falsa declaração pode ser legitimada ou não. Por fim, analisaremos o debate entre Kant e Benjamim Constant, sobre a problemática da mentira, onde será tratada a questão de um suposto direito de mentir e dos princípios gerais e intermediários, a saber, se é possível a aplicação de um princípio geral de forma absoluta isolada sem o auxílio de princípios intermediários.

PALAVRAS - CHAVE: Moral; Direito; Mentira.

\section{KANT AND THE LIE}

\footnotetext{
ABSTRACT:

In this article we will address the issue of lie, in Kant, linking moral issues. For being ethical and right branches of morality, the problem of lies is in

${ }^{1}$ Mestre em Filosofia pela Universidade Estadual do Ceará (UECE), Ceará - Brasil. Membro do Grupo de Pesquisa Direito, Moral e Política - GPOLIS da Universidade Estadual Vale do Acaraú (UVA). E-mail: francisco_eliandro@hotmail.com

${ }^{2}$ Mestrando em Filosofia pela Universidade Estadual do Ceará (UECE), Ceará - Brasil. Membro do Grupo de Pesquisa em Filosofia da Religião - GEPHIR da Universidade Estadual Vale do Acaraú (UVA). E-mail: jorge.lcl@hotmail.com
} 
whether it is ethical or legal question, or if it is a moral problem, which encompasses both the ethics and the right, that delegitimize such act. We start this unit with the analysis of moral concepts, ethics and law in order to understand what constitutes each of these cultural fields and which the distinction between the two. Then we will deal in particular the question of lies in practical philosophy of Kant, addressing their ethical position on the act of lying, which is raised the question whether a false statement can be justified or not. Finally, we will analyze the debate between Kant and Benjamin Constant, on the issue of lie, which will address the issue of a supposed right to lie and the general principles and intermediates, namely the application of a general principle it is possible absolute isolated without the aid of intermediate principles.

KEYWORDS: Moral; Right; Lie.

\section{Moral, ética e direito.}

É comum na maioria dos textos filosóficos, sobre Kant, observarmos os conceitos de moral e ética sendo tratados da mesma maneira, porém estes dois conceitos em Kant são distintos. Ele, em sua filosofia prática, distingue moral, ética e direito, especificando o que constitui cada um destes campos da cultura. ${ }^{3}$

Segundo Kant, o conceito de moral significa "uma prática no sentido objetivo, enquanto totalidade de leis que ordenam incondicionalmente, de acordo com as quais devemos agir." (KANT, 2013, p. 79). Para o filosofo alemão, a moral em certos casos, tem uma compreensão ampla, a ética e o direito fazem parte desta disciplina, ou seja, são ramos da moral. O termo moral vem adquirir sentido amplo a partir da distinção que Kant faz entre as leis da natureza e as leis da liberdade; para o filósofo as leis da liberdade são denominadas de leis morais. Kant divide as leis morais em duas áreas, leis morais jurídicas, que compreendem as ações exteriores, ou seja, o direito, e leis morais éticas, que dizem respeito ao fundamento subjetivo que determina a vontade no processo da ação.

A distinção entre os dois campos da moral, direito e ética reside na natureza do móbil, ou seja, na mola propulsora, subjetiva, que determina a vontade do arbítrio no processo da ação. No campo da ética, o que determina a ação é o conceito de dever, em outros termos, o móbil da ação é o próprio dever. $\mathrm{O}$ direito em Kant é compreendido da seguinte maneira, "direito é, portanto, a soma das condições sob as quais a escolha de alguém pode ser unida à escolha de outrem de acordo com uma lei universal da liberdade." (KANT, 2008, p 76).

\footnotetext{
${ }^{3} \mathrm{O}$ texto kantiano utilizado como principal fonte de pesquisa neste artigo, referente ao conceito de moral e a distinção entre ética e direito, será "A metafísica dos costumes". Em seu texto Kant aborda de maneira específica o direito e a ética como ramos da moral.
} 
Terra, acerca da distinção entre moral, ética e direito, afirma que;

Ao distinguir as leis da natureza das leis da liberdade, o termo 'moral' adquire sentido amplo, já que estas últimas são denominadas leis morais. Kant distingue leis morais jurídicas, que dizem respeito às ações exteriores, e éticas, que exigem que as próprias leis sejam os princípios de determinação das ações. A moral englobaria tanto o direito quanto a ética. (TERRA, 2004, p. 13,14).

O que determina se uma ação ocorre no campo da ética ou do direito é justamente a legislação que designa a ação, ou seja, a legislação que faz de uma "ação um dever e desse dever, por sua vez, um móbil, é ética. Mas a que não inclui o último na lei e, portanto, admite também outro móbil distinto da idéia mesma de dever, é jurídica." (KANT, 2008, p. 71). O direito e a ética distinguem-se, portanto, não tanto com relação aos diferentes deveres próprios, mas pela diferença de legislação que une um e outro impulso à lei. Em síntese, segundo Kant;

Os deveres de acordo com a legislação jurídica podem ser somente deveres externos, visto que essa legislação não requer que a idéia desse dever, que é interna, seja ela mesma o fundamento determinante da escolha do agente; e posto que necessita ainda de um motivo que se ajuste à lei, só pode relacionar motivos externos a si. Por outro lado, a legislação ética, embora também transforme ações internas em deveres, não exclui ações externas, mas se aplica a tudo que seja um dever em geral. Porém, precisamente porque a legislação ética inclui no interior de sua lei o motivo interno da ação (a idéia de dever), e este aspecto não deve estar presente na legislação externa, a legislação ética não pode ser externa (nem mesmo a legislação externa de uma vontade divina, ainda que realmente assuma deveres que se apóiam em uma outra, a saber, uma legislação externa ao torná-los, como deveres, motivos em sua legislação. (KANT, 2008, p. 72).

Para Kant, por mais que exista uma distinção entre leis morais jurídicas e leis morais éticas todas elas fazem parte da moral em sentido amplo, ou seja:

Moral, em sentido amplo, compreende a doutrina dos costumes englobando tanto o direito quanto a ética. Por isso, não se podem tomar como correlatos os pares moral/direito e moralidade/legalidade. Uma leitura que os identificasse levaria a uma separação entre direito e ética sem apontar os elementos comuns. (HECK, 2003, p. 191).

A fórmula imperativa de todo dever ético, também a lei do direito se pauta em um princípio moral. Pois, pode-se dizer que o sistema moral 
integra tanto a ética como o direito. O fato é que ambas as legislações de liberdade - a ética e o direito - são informadas pelo imperativo categórico e pela lei jurídica, respectivamente. Contudo, ambas estão subjugadas à lei moral imposta. Nesse sentido, a obrigatoriedade dos deveres nas duas legislações origina-se na razão prática e é manifestada através desses imperativos de ação.

A compreensão do conceito de moral em Kant requer que se precise melhor o sentido dos termos direito e ética. Vejamos nos próximos tópicos, de forma específica, o que constitui cada uma dessas disciplinas na filosofia prática de Kant.

\section{Ética}

O conceito de ética em Kant fundamenta-se e estrutura-se sobre a proposta de autonomia, em que o sujeito legisla suas próprias leis de ação por meio de um critério de universalização, segundo o qual a máxima da ação deve ser formulada da seguinte maneira, "age de modo que a máxima de tua ação possa tornar-se uma lei universal" (KANT, 2008, p.232), e pelo cumprimento do dever. Ela não admite outro móbil, que impulsione sua ação, a não ser o próprio dever. Na formulação kantiana da ética, o princípio que leva a um determinado agir é a própria lei, tal ética exige que o seu móbil seja o respeito pela lei moral. A ética kantiana fundamenta-se e estrutura-se sobre a proposta de autonomia.

O arbítrio, no momento ético, é compreendido como autônomo através da sua propriedade em legislar leis de ação para si mesmo. Esta autodeterminação ética da vontade tem como fundamento a observação do cumprimento do dever e o respeito pela lei moral, que foi legislada pelo próprio arbítrio. Portanto, a ética em Kant passa por um critério de universalização, porém a ação "é realizada não apenas conforme um princípio objetivo de determinação válido universalmente, mas também pelo dever, com um sentimento de respeito pela própria lei moral." (TERRA, 2004, p. 13,14).

Por fim, segundo Barbosa em sua dissertação "Direito e Moral em Kant", , a ação ética em Kant pode ser compreendida através de três ângulos. Vejamos:

1. "Primeiramente, essa ação deve ser realizada somente para obedecer à lei do dever e nada mais." (BARBOSA, 2006, p.55).

2. "Por conseguinte, a ação só é ética quando cumprida não segundo um fim externo, mas tão somente pela máxima que a determina (no caso, pelo princípio da vontade)." (Idem).

\footnotetext{
${ }^{4}$ Dissertação apresentada ao Programa de Pós-Graduação em Filosofia pela Faculdade de Filosofia e Ciências Humanas da Pontifícia Universidade Católica do Rio Grande do Sul.
} 
3. "Em terceiro e último lugar, uma ação pode ser considerada como ética quando não for movida por inclinação alguma a não ser pelo respeito à lei. Em suma, para essa ação ser aceita como válida moralmente, ela não pode ser apenas coerente com o dever, mas deve também ser cumprida por dever. Quer dizer, a legislação que erige uma ação como dever, e o dever, simultaneamente, como impulso (vontade imediata), é ética." (Idem).

Vimos até aqui, de um modo geral e específico, o que constitui os conceitos de moral e ética. De um modo geral expomos suas definições e o campo em que ambos atuam, e de modo específico apresentamos o que cada um desses conceitos representa na filosofia prática de Kant. Analisaremos, no tópico a seguir, o que constitui o conceito de direito em Kant. Para tal empreendimento tomaremos como obra fundamental a Metafísica dos Costumes.

\section{Direito}

Como observamos nos tópicos anteriores, Kant apresenta uma clara distinção entre ética e direito quanto à origem de cada ordenamento. $\mathrm{O}$ filósofo "distingue leis morais jurídicas, que dizem respeito às ações exteriores, e éticas, que exigem que as próprias leis sejam os princípios de determinação das ações." (TERRA, 2004, p.14). As leis morais jurídicas em Kant são representadas pelo conceito de direito ${ }^{5}$. O direito na perspectiva kantiana, como já mencionado, é formulado da seguinte maneira: "direito é, portanto, a soma das condições sob as quais a escolha de alguém pode ser unida à escolha de outrem de acordo com uma lei universal da liberdade." (KANT, 2008, p 76).

$\mathrm{O}$ direito em Kant visa possibilitar a boa convivência entre os arbítrios humanos, garantindo a liberdade de cada um por meio de uma legislação externa. Através do direito é possível aos arbítrios humanos viverem com suas diferenças, ou seja, a liberdade externa atribuída é uma condição através da qual a pluralidade pode ser contemplada num projeto jurídico-político.

\footnotetext{
${ }^{5} \mathrm{O}$ conceito de direito, segundo o Dicionário de Filosofia Nicola Abbagnanno, significa: "Em sentido geral e fundamental, a técnica da coexistência humana, isto é, a técnica que visa possibilitar a coexistência dos homens. Como técnica, o D. se concretiza em conjunto de regras (nesse caso leis ou normas), que têm por objetivo o comportamento intersubjetivo, ou seja, o comportamento dos homens entre si. Na história do pensamento filosófico e jurídico, sucederam-se ou entrecruzaram-se quatro concepções fundamentais sobre a validade do D. 1. A que considera que o D. positivo (conjunto dos D. que as várias sociedades humanas reconhecem) baseia-se num D. natural eterno, imutável e necessário ; 2. A que julga o D. fundado na moral e o considera, portanto, uma forma diminuída ou imperfeita da moralidade; 3. A que reduz o D. a força, ou seja, a uma realidade histórica politicamente organizada; 4. A que considera o D. como uma técnica social. (ABBAGNANO, 2007, p.442).
} 
Assim como na legislação ética, o direito está fundamentado sobre um critério de universalização, isto é, sobre um princípio de universalidade da lei moral. O direito, além de ser fundado sobre este critério, está também relacionado com a ideia de justiça, pois é por meio dele que julgamos se uma ação é justa ou não. Para que uma ação possa ser considerada justa, pelo direito, tal ação deve ser capaz de coexistir com a liberdade de todos segundo uma lei universal, pois a máxima do direito é formulada da seguinte maneira; "age externamente de modo que o livre uso de teu arbítrio possa coexistir com a liberdade de todos de acordo com uma lei universal", (KANT, 2008, p.77). Se no momento da ação a liberdade de escolha do arbítrio não puder coexistir com a liberdade de todos de acordo com uma lei universal, sua ação é considerada injusta. Disso conclui-se, que para Kant, tudo o que constitui um obstáculo à liberdade é injusto e que o afastamento desse obstáculo é, pela mesma forma, justo, ou seja;

Se, então, minha ação ou minha condição pode geralmente coexistir com a liberdade de todos de acordo com uma lei universal, todo aquele que obstaculizar minha ação ou minha condição me produz injustiça, pois este obstáculo (resistência) não pode coexistir com a liberdade de acordo com uma lei universal. (KANT, 2008, p 77).

O conceito de direito, segundo a perspectiva kantiana, abrange três elementos; a relação externa, a relação com a escolha do outro e a forma na relação de escolha por parte de ambos, isto é, o conceito de direito tem a ver com:

1. "Em primeiro lugar, somente com a relação externa e, na verdade, prática de uma pessoa com outra, na medida em que suas ações, como fatos, possam ter influência (direta ou indireta) entre $\mathrm{si}^{6}$." (KANT, 2008, p 76).

2. "Em segundo lugar, não significa a relação da escolha de alguém com a mera aspiração (daí, por conseguinte, com a mera necessidade) de outrem, como nas ações de beneficência ou crueldade, mas somente uma relação com a escolha do outro ${ }^{7}$." (KANT, 2008, p 76).

3. "Em terceiro lugar, nessa relação recíproca de escolha, não se leva de modo algum em conta a matéria da escolha, isto é, o fim que cada

\footnotetext{
${ }^{6}$ Salgado, acerca desta perspectiva kantiana, afirma que "todo direito é uma relação entre seres humanos (só o ser humano se envolve numa relação prática), na medida em que tal relação se mostre como ação que, como fato, possam exercer influência, num e noutro, direta ou indireta." (SALGADO, 1995, p.270).

${ }^{7}$ Comenta Salgado que "essa relação prática e externa estabelece-se entre um arbítrio e outro e não entre o arbítrio do individuo e o desejo de outro (wunsch), como nos atos de benemerência (wohlttigkeit), ou de crueldade do estado de natureza, de amor ou de poder. Em lugar dessas relações, surgem as do direito como relações arbitrárias, da disposição da vontade alheia por meio do contrato (particular) ou da lei (geral)." (ibidem)
} 
um tem em mente como o objeto de seu desejo; não é indagado, por exemplo, se alguém que compra mercadorias de mim para o seu próprio uso comercial ganhará com a transação ou não. Tudo que está em questão é a forma na relação de escolha por parte de ambos, porquanto a escolha é considerada meramente como livre e se a ação de alguém pode ser unida com a liberdade de outrem em conformidade com uma lei universal ${ }^{8}$." (KANT, 2008, p 77).

$\mathrm{O}$ direito pode ser representado como uma coação geral e recíproca, de tal modo que, para Kant, direito e faculdade de coagir significam a mesma coisa. Ele está ligado à competência de exercer coerção, pois, para Kant, tudo que é considerado injusto apresenta-se como um obstáculo à liberdade segundo leis universais. Conseqüentemente, para o filósofo:

[...] se um certo uso da liberdade é ele próprio um obstáculo à liberdade de acordo com uma lei universal (isto é, é injusto), a coerção que a isso se opõe (como um impedimento de um obstáculo à liberdade) é conforme à liberdade de acordo com leis universais (isto é, é justa). Portanto, ligada ao direito pelo princípio de contradição há uma competência de exercer coerção sobre alguém que o viola. (KANT, 2008, p. 79).

Conclui-se que, no direito, a partir de uma perspectiva kantiana, o agente encontra-se determinado de modo a priori pela lei do direito, a qual implica na coexistência de sua liberdade com as demais liberdades subjetivas por meio de uma lei universal. Dessa forma, o direito requer uma adequação externa de meu arbítrio às condições que tornam possível sua coexistência universal com o arbítrio dos demais. A não observação deste princípio, ou seja, quando uso da minha liberdade com respeito às demais liberdades não for possível, então a injustiça impera sobre meu direito. É a simples conformidade à lei que importa.

Até o presente momento, expomos a estrutura da filosofia prática em Kant, apresentando os conceitos de ética e direito como ramos da moral, ou seja, a moral em uma compreensão ampla engloba tanto o direito quanto a ética. Vejamos, no tópico a seguir, a aplicação da moral kantiana sobre um dos problemas que, desde os primórdios, ocupará a reflexão ético-filosófica, a saber, o problema da mentira.

\footnotetext{
${ }^{8}$ Segundo Salgado, "a relação puramente formal entre os arbítrios recíprocos, razão pela qual não se leva em conta o conteúdo da vontade ou matéria do arbítrio. Não interessa que objetivo alguém teve ao contrair um determinado contrato, se há um equilíbrio de vantagens ou desvantagens. Exige-se tão só que, no ato da vinculação, haja liberdade formal dos arbítrios no sentido de uma independência com relação 'ao arbítrio coator de outro', segundo um principio de igualdade inata e natural, definida como a liberdade 'de não ser obrigado pelos outros a fazer mais do que o a que eles reciprocamente também possam ser obrigados'." (SALGADO, 1995, p.271).
} 


\title{
Kant e a mentira
}

O problema da mentira ${ }^{9}$, desde os primórdios, sempre ocupara um espaço na reflexão ético-filosófica, inúmeros foram os filósofos que abordaram vinculando-a à questões de natureza ética e do direito, fazendo uma análise da possibilidade de um direito de mentir, ou da legitimidade da mentira. Vejamos em especial o caso da mentira em Rousseau e Kant.

Para Rousseau o conceito de mentira significa o ato de afirmar uma coisa em vantagem própria causando prejuízo a outrem. Porém se tal ato não visa a nenhum proveito nem causa prejuízo a ninguém ele não pode ser considerado uma mentira e sim uma ficção. Segundo o filósofo a mentira está diretamente relacionada com o proveito e prejuízo. Pois:

\begin{abstract}
Mentir para sua própria vantagem é impostura, mentir para a vantagem de outrem é fraude, mentir para prejudicar é calunia; é a pior espécie de mentia. Mentir sem proveito nem prejuízo para si nem para outrem não é mentir: isso não é mentira, é ficção. (ROUSSEAU cit. in PUENTE, 2002, p.40) ${ }^{10}$.
\end{abstract}

Rousseau em seu texto "Devaneios do passeante solitário (Quarto passeio, 1777)", levanta duas questões, para exame, relacionadas com o caso da mentira. A primeira questão aborda o problema de quando se deve a outrem a verdade, ${ }^{11}$ visto que para o filosofo não se a deve sempre. Poderíamos formular desta questão o seguinte problema: Calar uma verdade a qual não se está obrigado a dizer é mentir ou fazer uma falsa declaração sem proveito nem prejuízo é mentir? A segunda questão pode ser formulada por meio da pergunta: Há casos em que se possa enganar inocentemente? Ou seja, todo aquele que não diz o que é verdadeiro é injusto? Vejamos a analise que Rousseau faz destes dois problemas e sua resolução.

\footnotetext{
${ }^{9}$ Segundo o Dicionário Filosófico de André Comte-Sponville, a mentira é o ato de "dizer, com intenção de enganar (e não por antífrase ou por ironia), o que se sabe ser falso. Toda mentira supõe um saber e, pelo menos, a idéia de verdade. É por isso que a mentira recusa a sofística, que a desculpa. O paradoxo do mentiroso (v. "mentiroso, paradoxo do") mostra suficientemente que a mentira só é possível a título de exceção: assim, ela confirma a própria regra que viola ("a norma da ideia verdadeira dada", diria Espinosa) e que a torna possível. Azar o dos mentirosos e dos sofistas. (COMTE, 2003, p.381)

${ }^{10} \mathrm{O}$ texto "Devaneios do passeante solitário (Quarto passeio, 1777)" de Rousseau, utilizado neste artigo, está contido no livro "Os filósofos e a mentira" organizado por Fernando Rey Puente.

${ }^{11}$ A questão levantada por Rousseau em seu texto foi um dos principais temas abordado por Benjamin Constante em sua obra "Das reações políticas (Dos princípios)", nesta obra Constant, fazendo uma crítica Kant, afirma que "dizer a verdade só é, portanto, um dever em relação àqueles que têm direito à verdade. Ora, nenhum homem que prejudica os outros tem direito à verdade." (CONSTANT cit. in PUENTE, 2002, p.68).
} 
- Primeira questão:

Às verdades que não tem nenhuma utilidade, nem para a instrução, nem para a prática, como seriam um bem devido, porquanto não são nem mesmo um bem, e visto que a propriedade não é fundamentada se não na utilidade, na qual não há de nem um modo utilidade possível, não pode haver propriedade. Pode-se reclamar um terreno ainda que estéril, porque se pode ao menos habitar o seu solo: porém se é um fato inútil, indiferente em todos os aspectos e sem consequências para ninguém seja verdadeiro ou falso, isso não interessa a ninguém. Na ordem moral nada é inútil, assim como na ordem física. Nada pode ser devido daquilo que nada serve; para que uma coisa seja devida, é preciso que seja ou possa ser útil. Assim, a verdade devida é aquela que interessa à justiça; é profanar o nome sagrado da verdade, aplicá-las às coisas vãs, cuja existência é indiferente a todos, e cujo conhecimento é inútil a tudo. A verdade, despojada de qualquer espécie de utilidade mesmo possível, não pode portanto, ser uma coisa devida e, consequentemente, aquele que a silencia ou a dissimula de nem um modo mente. (ROUSSEAU cit. in PUENTE, 2002, p.36,37).

- Segunda questão:

Não dizer o que é verdadeiro e dizer o que é falso são duas coisas muito diferentes, porém deles pode resultar, entretanto, o mesmo efeito, pois esse resultado é seguramente o mesmo, todas as vezes em que esse efeito é nulo. Em toda parte onde a verdade é indiferente, o erro contrário é também indiferente; dai se sucede que, em semelhante caso, aquele que engana dizendo o contrário da verdade não é mais injusto do que aquele que engana não a declarando; pois, em matéria de verdades inúteis, apenas a ignorância é pior do que o erro. Que eu creia ser a areia do fundo do mar branca ou vermelha, isso não mais me importa do que ignorar a sua cor. Como se poderia ser injusto não se prejudicando a ninguém, visto que a injustiça não consiste senão no dano causado a outrem? (ROUSSEAU cit. in PUENTE, 2002, p.37).

Segundo Rousseau o ato de afirmar uma coisa falsa só pode ser considerado mentira se causar prejuízo para aquele que fez tal afirmação ou a outrem, em outros termos, qualquer que seja a declaração, verdadeira ou falsa, não causando prejuízo a ninguém nunca poderá ser chamada de mentira. A mentira para o filósofo é um ato externo, pois, sempre causa prejuízo a outrem. Porém, em Kant, o conceito de mentira é compreendido de maneira diferente, ele rompe ${ }^{12}$ com a concepção de Rousseau sobre a

\footnotetext{
12 Este rompimento acontece em especial no campo moral, na doutrina do direito a concepção kantiana da mentira aproxima-se da concepção de Rousseau.
} 
mentira. Para o filósofo de Königsberg qualquer inverdade intencional, causando ou não prejuízo a outrem, sempre será mentira, pois ela rompe com a máxima, que é um mandamento sagrado da razão, ser verídico em todas as declarações. Vejamos o caso da mentira em Kant.

A mentira segundo Kant é conceituada, no sentido ético da palavra, como inverdade intencional em geral. Ela é um ato que não precisa ser doloso aos outros para ser repudiada. Para o filósofo, a maior violação que um arbítrio pode cometer, em questão do dever de um ser humano consigo mesmo meramente como ser ético, é a inverdade, ou seja, a mentira. Pois, através dela um ser humano descarta e, por assim dizer, aniquila sua dignidade. A mentira, independente de qual seja, é inadmissível porque torna o homem indigno. modos:

$\mathrm{Na}$ filosofia prática de Kant o conceito de mentira é tratado de dois

\begin{abstract}
Na doutrina do direito, uma inverdade intencional é chamada de mentira somente se violar o direito de outrem; mas na ética, onde nem uma autorização é derivada da inocuidade, fica claro de per si que nenhuma inverdade intencional na manifestação dos pensamentos de alguém pode eximir-se dessa áspera denominação, pois a desonra (sendo um objeto de desprezo moral) que acompanha uma mentira também acompanha um mentiroso, como sua sombra. (KANT, 2008, p.271).
\end{abstract}

A mentira pode ser interna por meio da manifestação do pensamento ou externa quando viola o direito de outrem, como observado na citação acima. $\mathrm{O}$ ato de mentir, ou seja, a inverdade intencional na doutrina do direito só é considerada mentira somente se violar o direito de outrem. Porém para Kant, a mentira "prejudica sempre uma outra pessoa, mesmo quando não um outro homem determinado e sim a humanidade em geral, ao inutilizar a fonte do direito." (KANT, 2013, p. 79). Pois o direito é fundado sobre o princípio de veracidade, em que a razão ordena, incondicionalmente como máxima, (e não admite qualquer exceção seja qual for a espécie de conveniência), o seguinte mandamento: ser verídico em todas as declarações. O princípio de veracidade é a base da doutrina do direito em que todos os acordos são fundados sobre ele. Na ética, qualquer inverdade intencional, por mais que seja somente interna na manifestação do pensamento, e teoricamente não prejudique ninguém, nunca poderá eximirse deste nome tão desonroso ${ }^{13}$.

Vejamos, por exemplo, o caso da mentira em que Kant expõe na Fundamentação da Metafísica dos Costumes, como exemplo célebre para mostrar que uma mentira, por mais que seja bem intencionada, nunca poderá

\footnotetext{
${ }^{13}$ Para Rousseau, a inverdade intencional que não visa proveito nem prejudica a outrem não pode ser considerada como mentira e sim como uma simples ficção. Cf. (ROUSSEAU cit. in PUENTE, 2002, p.40)
} 
ser aceita, pois uma máxima que não possa ser universalizada, por si só destruir-se-ia a si mesma necessariamente. Segundo Kant, "Não posso eu, quando me encontro em apuro, fazer uma promessa com a intenção de a não cumprir?" (KANT, 2009, BA 19,20: p.35,36). O filósofo de Königsberg distingue aqui facilmente os dois sentidos que a questão pode ter, ou seja, a realização de uma falsa promessa, quando me encontro em apuro, é prudente ou é conforme ao dever.

O primeiro caso pode sem dúvida apresentar-se muitas vezes. É verdade que vejo bem que não basta furtar-me ao embaraço presente por meio desta escapatória, mas que tenho de ponderar se desta mentira me não poderão advir posteriormente incômodos maiores do que aqueles de que agora me liberto; e como as consequências, a despeito da minha pretensa esperteza, não são assim tão fáceis de prever, devo pensar que a confiança uma vez perdida me pode vir a ser mais prejudicial do que todo o mal que agora quero evitar; posso enfim perguntar se não seria mais prudente agir aqui em conformidade com uma máxima universal e adquirir o costume de não prometer nada senão com a intenção de cumprir a promessa. Mas em breve se me torna claro que uma tal máxima tem sempre na base o receio das consequências.Ora ser verdadeiro por dever é uma coisa totalmente diferente de sê-lo por medo das consequências prejudiciais; enquanto no primeiro caso o conceito da ação em si mesma contém já para mim uma lei,no segundo tenho antes que olhar à minha volta para descobrir que efeitos poderão para mim // estar ligados à ação. Porque, se me afasto do princípio do dever, isso é de certeza mau; mas se for infiel à minha máxima de esperteza, isso poderá trazer-me por vezes grandes vantagens, embora seja em verdade mais seguro continuar--lhe fiel. (KANT, 2009, BA 18,19: p.35).

O imperativo categórico é estabelecido por Kant como guia que determina a ação perante uma situação de conflito. Kant, para resolver da maneira mais rápida e segura a questão colocada acima, se uma falsa promessa é aceitável ou não, aplica a fórmula do imperativo categórico de duas maneiras, que consiste em perguntar a mim mesmo:

- Ficaria eu satisfeito de ver a minha máxima (de me tirar de apuros por meio de uma promessa não verdadeira) tomar o valor de lei universal (tanto para mim como para os outros)?

- E poderia eu dizer a mim mesmo: - Toda a gente pode fazer uma promessa mentirosa quando se acha numa dificuldade de que não pode sair de outra maneira?

O filósofo reconhece que qualquer um em verdade pode querer a mentira em determinada situação de apuro, porém, por mais que alguém escolha mentir em tal situação, nunca desejará uma lei universal de mentir; pois,se houvesse tal lei,não existiria promessa alguma,haja visto que seria 
improvável alguém acreditar em outra pessoa ao afirmar a sua vontade relativamente às suas futuras ações, se por ventura alguém apressadamente acreditasse, tal pessoa pagaria na mesma moeda. Por certo se tal máxima fosse transformada em lei universal, levaria a uma contradição e por isso se destruiria a si mesma.

Podemos citar, para uma melhor compreensão do caso da mentira em Kant, o exemplo clássico do indivíduo tomado de fúria assassina que pergunta se o vosso amigo, perseguido por ele, não está refugiado em vossa casa. A questão contida neste exemplo é se devo ser inverídico a uma certa declaração de que não se pode desviar-se, a fim de evitar um crime que ameaça outra pessoa. Segundo Kant, por maior que seja o prejuízo decorrido da veracidade em uma declaração que não se pode evitar, nunca devemos escolher a inverdade ao invés da verdade. Pois, de acordo com o filósofo:

A veracidade nas declarações que não se pode evitar é um dever formal do homem com relação a qualquer outro, por maior que seja o prejuízo decorrente disso para ele ou para outra pessoa; e se não cometo uma injustiça contra aquele que me obriga a uma declaração de maneira injusta, se as falsifico, cometo, por essa falsificação, que também pode ser chamada mentira (embora não no sentido dos juristas), em geral uma injustiça na parte mais essencial do dever: isto é, faço, naquilo que a mim se refere, com que as declarações em geral não encontrem mais crédito, e portanto também todos os direitos fundados em contratos sejam abolidos e percam a força; isto é uma injustiça causada à humanidade em geral. (KANT, 2013, p. 73).

Portanto, para Kant, a razão ordena incondicionalmente e não aceita limitação para o princípio de ser verídico em todas as declarações. A mentira por mais que seja bem intencionada é inadmissível ${ }^{14}$, pois, por meio dela um ser humano faz de si mesmo um objeto de desprezo aos olhos dos outros e quebra todos os direitos fundados em contrato. Resumindo, segundo o filósofo de Königsberg, a mentira é:

[...] uma declaração deliberadamente falsa feita a um outro homem, não precisa do suplemento que teria de prejudicá-lo, como os juristas o exigem para sua definição (mendacium est falsiloquium in praeiudicium alterius). Pois, na medida em que torna inutilizável a fonte do direito, ela sempre prejudica outrem, mesmo que não a um outro homem, pelo menos sim a humanidade em geral. (KANT, 2013, p. 74).

\footnotetext{
${ }^{14} \mathrm{~A}$ condenação moral da mentira é também princípio ético tradicional da cultura cristã. Passagens bíblicas podem mostrar a adoção dessa posição: "Não dirás falso testemunho contra teu próximo" (Êxodo 20,16) ou "Os lábios mentirosos são abomináveis ao Senhor; mas os que praticam a verdade são o seu deleite" (Provérbios 12,22). A mentira é, em suma, considerada uma nódoa vergonhosa na conduta humana.
} 
O posicionamento de Kant, acerca da mentira, será duramente criticado pelo filósofo francês Benjamin Constant em sua obra "Das reações políticas (Dos princípios)"15, ao afirmar que se o principio de veracidade, dizer a verdade é um dever, fosse tomado incondicionalmente $\mathrm{e}$ isoladamente, tornaria impossível a existência de qualquer sociedade. Constant em sua crítica afirma que, "dizer a verdade só é, portanto, um dever em relação àqueles que têm direito à verdade" (CONSTANT cit. in PUENTE, 2002, p. 68). Ao afirmar tal posicionamento Constante abre a possibilidade de se pensar em uma legitimação da mentira. Observemos no tópico a seguir a crítica de Constant a Kant.

\section{A crítica de Constant a Kant}

Kant foi duramente criticado por seu posicionamento moral sobre a mentira, ao afirmar que a mentira, independente de qual seja, é inadmissível porque torna o homem indigno. O princípio moral kantiano, que dizer a verdade é um dever, em outros termos, o princípio de veracidade nas declarações, não aceita exceções, pois, é um principio absoluto, em que a razão ordena categoricamente este dever. O filósofo francês Benjamin Constant, em um artigo intitulado "Das reações políticas"16, faz uma crítica $^{17}$ direta a Kant ao afirmar que se adotássemos o dever de dizer a

\footnotetext{
${ }^{15}$ O texto "Das reações políticas (Dos princípios)" de Benjamin Constant, utilizado neste artigo, está contido no livro "Os filósofos e a mentira" organizado por Fernando Rey Puente.

16 “A obra Des réactions politiques, de Benjamin Constant, foi originariamente publicada a 30 de março de 1797 - o capítulo 8 (Des Principes) pode encontrar-se em Benjamin-Henri Constant de Rebecque, Cours de politique constitutionnelle et collection des ouvrages publiés sur le Gouvernementreprésentatif. Genève, vol. 2, Slatkin Reprints, 1982, pp. 70128. Uma versão completa deste capitulo e do ensaio de Kant que lhe dá resposta ("Über ein vermeintes Recht aus Menschenliebe zu lügen" - Sobre um pretenso direito de mentir por amor aos homens) encontra-se em François Boituzat, Un droitde mentir? Constant ou Kant. Paris, PUF, 1993, pp. 102-112. Trata-se, para Constant, de justificar nesta obra a Constituição de 1795 (a Constituição do ano III) ao absolver os princípios que inspiram essa Constituição do descrédito no qual caíram. Contra aqueles que defendem, em 1797, um retorno ao Antigo Regime, Constant pretende, ao defender os princípios de 1789, não apenas preservar esses princípios de suas conseqüências ruinosas de 1793 mas sustentar a república estabelecida. A Revolução francesa não se confunde para Constant com os excessos cometidos em seu nome. (Nota da tradutora)". (PUENTE, 2002, p. 59).

${ }^{17}$ Oswaldo Giacóia Junior, na introdução do livro "Os filósofos e a mentira" que constitui uma coletânea de textos filosóficos organizado por Fernando Rey Puente, comenta que "a célebre controvérsia entre Benjamin Constant e Immanuel Kant a propósito de um direito de mentir, por razões humanitárias, nos proporciona uma rara e curiosa oportunidade de perceber o ardor e o engajamento com que o pensamento iluminista - em seu empenho para formular e resolver os problemas fundamentais de seu tempo, entre eles, principalmente, a tarefa pedagógica de educar o público e, por esse meio, concorrer para o progresso e elevação moral do gênero humano - se envolveu numa questão que, desde os primórdios, ocupara a reflexão ético-filosófica, a saber, o problema da mentira. (PUENTE, 2002, p. 9).
} 
verdade como um dever absoluto, incondicional, a sociedade humana tornar-se-ia simplesmente impossível. Em seu texto o filósofo aborda o tema da mentira, fazendo uma relação com a questão da natureza do direito, analisando a possibilidade de um direito de mentir, ou da legitimidade da mentira. Vejamos o trecho do texto em que o filósofo crítica Kant:

O princípio moral que declara ser um dever dizer a verdade, se alguém o tomasse incondicional e isoladamente, tornaria impossível qualquer sociedade. Temos a prova disso nas consequências muito imediatas que um filósofo alemão tirou desse princípio, indo até o ponto de afirmar que a mentira dita a um assassino que nos perguntasse se um amigo nosso perseguido por ele não se refugiou em nossa casa seria um crime. (KANT, 2013, p. 72).

Constant refuta o princípio ético kantiano, da total condenação moral da mentira, afirmando que sua aplicação absoluta e isolada é impossível. Segundo o filósofo, é somente por meio de princípios intermediários que a aplicação deste princípio é possível. Em sua crítica a Kant, ele não nega a validade do princípio que dizer a verdade é um dever, porém, a crítica restringe-se ao meio de aplicação deste princípio:

Dizer a verdade é um dever. O que é um dever? A idéia de dever é inseparável da idéia de direitos: um dever é o que, em um ser, corresponde aos direitos de um outro. Lá onde não há direitos, não há deveres. Dizer a verdade só é, portanto, um dever em relação àqueles que têm direito à verdade. Ora, nenhum homem tem direito à verdade que prejudica a outrem. (KANT, 2013, p. 73).

O filosofo francês em seu texto aborda dois problemas, o primeiro é a impossibilidade de aplicação de um princípio $^{18}$ geral sem o auxílio de princípios intermediários, e o segundo problema restringe-se à pergunta, a quem temos o dever de dizer a verdade, ou seja, quem tem direito à verdade? Para Constant, os princípios gerais e abstratos necessitam ser conjugados a princípios intermediários para que seja possível sua aplicação, pois os princípios intermediários fazem elos de mediação entre os princípios gerais e casos concretos. Desta forma:

Quando se lança de repente, no meio de uma associação de homens, um primeiro princípio, separado de todos os princípios intermediários, que o fazem descer até nós e o ajustam à nossa situação, produz-se, sem dúvida, uma grande desordem: pois o princípio arrancado de todas as suas imediações, privado de

\footnotetext{
18 Segundo Constant, "Um princípio é o resultado geral de um certo número de fatos particulares. Todas as vezes que o conjunto desses fatos sofre algumas mudanças, o princípio que disso resultaria se modifica, porém essa modificação mesma torna-se princípio." (CONSTANT cit. in PUENTE, 2002, p. 67).
} 
todos seus apoios, rodeado de coisas que lhe são contrárias, destrói e abala; mas não é a culpa do primeiro princípio que é adotado; é a dos princípios intermediários que são desconhecidos: não é a admissão daquele, mas é a ignorância a respeito destes que afunda tudo no caos. (CONSTANT cit. in PUENTE, 2002, p. 62).

Constant para melhor expor a relação e importância que existe entre princípios gerais e princípios intermediários, utiliza um exemplo político, em que é "um princípio universal, igualmente verdadeiro em todos os tempos e em todas as circunstâncias, que nenhum homem pode estar submetido a leis, a não ser àquelas para as quais contribuiu," (CONSTANT cit. in PUENTE, 2002, p. 65). Se tomarmos este princípio de forma geral e isolada, sem a mediação de um principio intermediário, sua aplicação só seria possível em uma sociedade muito restrita, nesta sociedade ele poderia ser aplicado de maneira imediata e não precisaria de nenhum princípio intermediário, porém, em uma sociedade muito numerosa este princípio seria inaplicável. Para que fosse possível a aplicação deste princípio em uma sociedade mui numerosa, seria necessário acrescentar a tal princípio um princípio intermediário que seria formulado da seguinte maneira: os indivíduos podem "contribuir para a formação das leis, seja pessoalmente, seja por meio de seus representantes. ${ }^{19}$ " (CONSTANT cit. in PUENTE, 2002, p. 66). Pois, segundo Constant:

Qualquer um que quisesse aplicar a uma sociedade numerosa o primeiro princípio sem empregar o intermediário, a perturbaria infalivelmente. Mas esse abalo, que atestaria a ignorância ou a inépcia do legislador, nada provaria contra o princípio. $\mathrm{O}$ Estado não seria abalado porque se teria reconhecido que cada um dos seus membros deve contribuir para a formação das leis, mas porque se teria ignorado que, no excedente de um número dado, ele devia, para contribuir com essa formação, fazer-se representar. (CONSTANT cit. in PUENTE, 2002, p. 62).

Do ponto de vista de Constant, o que leva um princípio demonstrado como verdadeiro ser inaplicável, é o fato de ser ignorado o princípio intermediário que contém o meio da aplicação. $\mathrm{O}$ autor em sua crítica a Kant, afirma que se fosse considerado de uma maneira absoluta e isolada o princípio kantiano, que dizer a verdade é um dever, ele destruiria a sociedade. Porém se tal princípio for rejeitado, a sociedade não será menos destruída, pois deste modo, todos os alicerces da moral seriam abalados. Segundo Constant, a resolução deste problema encontra-se em admitir o

\footnotetext{
${ }^{19}$ Ao utilizar este exemplo, o filósofo francês retoma o artigo 6 da Declaração dos direitos do homem e do cidadão, de 26 de agosto de 1789: "A lei é a expressão da vontade geral. Todos os cidadãos têm direito de contribuir pessoalmente, ou pelos seus representantes, para a formação da lei. (...)." (PUENTE, 2002, p. 62).
} 
princípio intermediário que afirma: "dizer a verdade só é, portanto, um dever em relação àqueles que têm direito à verdade." (CONSTANT cit. in PUENTE, 2002, p. 68). Em síntese, o meio de aplicação do princípio kantiano da veracidade é através do princípio intermediário citado. Pois, de acordo com o filósofo francês:

\begin{abstract}
Princípios abstratos e gerais necessitam ser conjugados a princípios intermediários, encarregados de efetuar a mediação indispensável para sua aplicação aos casos concretos: a hierarquia seria, pois, a seguinte: princípios gerais abstratos, princípios intermediários (elos de mediação), casos concretos. (CONSTANT cit. in PUENTE, 2002, p. 69).
\end{abstract}

A aceitação do princípio intermediário, em que dizer a verdade só é um dever em relação àquele que têm direito à verdade, equivale na legitimação da mentira ou em um direito de mentir. Constante justifica seu posicionamento sobre um possível direito de mentir, a partir do conceito de dever. Para o filósofo, o dever "é o que, em um ser, corresponde aos direitos de um outro." (CONSTANT cit. in PUENTE, 2002, p. 68). Segundo o filósofo, o conceito de dever está diretamente relacionado com o conceito de direito, pois onde não há direitos, não há deveres. Na concepção do autor, há casos em que um direito de mentir é legitimado, por exemplo, no caso de uma declaração que não se pode evitar, se fôssemos inquiridos por um assassino, armado e disposto a matar, sobre a presença em nossa casa de um nosso amigo que lá tivesse buscado refúgio. A mentira neste caso, conforme Constant, seria legitimada, pois, nenhum homem que queira prejudicar a outro tem direito à verdade e onde não há direitos não há deveres.

\title{
A resposta de Kant à crítica de Constant
}

Kant, em resposta a crítica de Benjamin Constant, elaborou um texto intitulado "Sobre um suposto direito de mentir por amor à humanidade" ${ }^{20}$. O texto começa pela crítica ao princípio intermediário formulado por Constant: "Dizer a verdade só é, portanto, um dever em relação àqueles que têm direito à verdade.” (KANT, 2013, p.72). Para o filósofo alemão, esse

\footnotetext{
${ }^{20} \mathrm{O}$ texto de Kant, "Uber ein vermeintes Recht aus Menschenliebe zu lugen" ("Sobre um pretenso direito de mentir por amor aos homens") foi publicado no número de 6 de setembro de 1797 da revista Berlinische Blatter. A edição alemã a partir da qual foi feita sua tradução é da Academia de Berlin: Kant's gesammelte Schriften, herausgegeben von der Preussischen Akademie der Wissenschaften (Ak., v.VIII. p. 423 - 430). Os textos mais importantes de Kant que tratam da mentira e veracidade foram reunidos por G.Geismann e H. Oberer, no volume Kant und das Rechts der luge (Wurzburg, Koningshausen Neumann, 1986). Além do capítulo VIII Das reações políticas de Benjamin constant, encontram-se também, nesse volume, ensaios de H. Paton, J. Ebbinghaus, N. Gillespie, H. Wagner e de J. Vuillemin sobre esse tema. (Nota dos tradutores).”(PUENTE, 2002, p. 71).
} 
proton pseudos, seria o erro primário de Constant do qual derivam todos os outros, pois, é um engano de natureza semântica, visto que, de acordo com Kant:

[...] a expressão 'ter direito à verdade' é desprovida de sentido. Objetivamente ter direito a uma verdade, significa o mesmo que dizer: que depende da sua vontade, como em geral nas questões sobre o meu e o teu, que uma dada proposição deva ser verdadeira ou falsa, o que produziria então uma estranha lógica. (KANT, 2013, p.73).

Constant e Kant possuem concepções diferentes relativas aos primeiros princípios da moral e do direito. Para Constant, esses princípios são obtidos por meio de uma generalização a partir de fatos empíricos. Cita o filósofo:

Um princípio é o resultado geral de um certo número de fatos particulares. Todas as vezes que o conjunto desses fatos sofre algumas mudanças, o princípio que disso resultaria se modifica, porém essa modificação mesma torna-se princípio." (CONSTANT cit. in PUENTE, 2002, p. 61).

O filósofo em sua citação afirma que os princípios necessariamente mudam quando muda significativamente o conjunto considerado de fatos, e o seu alcance podendo ser restrito pelas exigências de aplicabilidade, que são expressas por princípios intermediários. Em Kant, os princípios da moral e do direito são estabelecidos (formulados e justificados) a priori e não podem sofrer modificações em função de problemas da sua aplicação aos fatos da experiência prática. Pois, segundo o filósofo alemão: "Um princípio reconhecido como verdadeiro por conseguinte nunca deve ser abandonado, mesmo que se encontre nele aparentemente também um perigo." (KANT, 2013, p.75).

Kant logo após ter refutado o princípio intermediário de Constant, afirmando que tal princípio é desprovido de sentido, passa ao exame do próprio princípio da veracidade, por meio de duas questões.

1. A primeira questão consiste em saber se o homem, quando não pode se recusar a responder sim ou não, tem a faculdade (o direito), de ser inverídico. (KANT, 2013, p. 73).

2. A segunda questão consiste em saber se não está absolutamente obrigado, em uma certa declaração a que o obriga uma injusta coação, a ser inverídico, a fim de evitar um crime que o ameaça ou ameaça outra pessoa. (KANT, 2013, p. 73).

Em resposta à primeira questão, Kant utiliza o princípio da veracidade para mostrar que independente da circunstância, por mais bondosa que possa ser a intenção, não devemos mentir, pois é uma ordem 
categórica o dever de ser verídico em todas as declarações. Vejamos a resposta de Kant a esta questão:

\begin{abstract}
A veracidade nas declarações, que não se pode evitar, é o dever formal do homem em relação seja a quem for, por maior que seja a desvantagem que daí decorre para ele ou para outrem; e se não cometo uma injustiça contra quem me força injustamente a uma declaração, se a falsificar, cometo em geral, mediante tal falsificação, que também se pode chamar mentira (embora não no sentido dos juristas), uma injustiça na parte mais essencial do Direito: isto é, faço, tanto quanto de mim depende, que as declarações não tenham em geral crédito algum, por conseguinte, também que todos os direitos fundados em contratos sejam abolidos e percam a sua força - o que é uma injustiça causada à humanidade em geral. (KANT, 2013, p. 74).
\end{abstract}

A definição kantiana do conceito de mentira, inverdade intencional, em parte, diferencia-se da definição que os juristas apresentam (mendacium est falsiloquium in praejudic ium alterios). Segundos os juristas uma declaração intencional não verdadeira é uma mentira na medida em que prejudica a outrem. Porém para Kant não há necessidade de acrescentar que ela deva lesar alguém, pois, uma falsa declaração sempre prejudica a humanidade, ao tornar inútil a fonte do direito. Sendo assim, por mais bondosa que possa ser a intenção no ato de mentir, mesmo que seja para impedires um assassinato, nunca teríamos o direito de ser inverídico, porque tal ato sempre prejudica "uma outra pessoa, mesmo quando não um outro homem determinado e sim a humanidade em geral." (KANT, 2013, p. 73).

A segunda questão é respondida por meio do exemplo que fora criticado por Constant. Neste exemplo Kant responde a crítica do filósofo francês e refuta uma possível legitimação da mentira ou um suposto direito de mentir. Cita Kant:

Por exemplo, se impedires, por meio de uma mentira, um indivíduo que agora mesmo, tomado de fúria assassina, ia cometer um assassínio, és responsável quanto ao aspecto jurídico por todas as consequências que daí possam advir. Mas se te restringes à estrita verdade, a justiça pública em nada te pode atingir, por mais imprevistas que sejam as consequências. É por conseguinte possível que tu, depois de teres honestamente respondido "sim" à pergunta do assassino relativa à presença em tua casa da pessoa odiada perseguida por ele, esta tenha ido embora sem ser notada, não estando mais ao alcance do assassino, e o crime portanto não seja cometido; se porém tivesses mentido e dito que a pessoa perseguida não estava em casa, e ela tivesse realmente saído (embora sem teres conhecimento disso), e depois o assassino a encontrasse fugindo e executasse sua ação, com razão poderias ser acusado de autor da morte dela. Pois se tivesses dito a 
verdade, tal como a conhecias, talvez o assassino, ao procurar seu inimigo na casa, fosse preso pelos vizinhos que acudissem, e o crime teria sido impedido. Por conseguinte, quem mente, por mais bondosa que possa ser sua intenção, deve responder pelas consequências de sua ação, mesmo diante do tribunal civil, e se penitenciar dela, por mais imprevistas que possam ser essas consequências; porque a veracidade é um dever que deve ser considerado a base de todos os deveres a serem fundados sobre um contrato, e a lei desses deveres, desde que se lhe permita a menor exceção, torna-se vacilante e inútil. (KANT, 2013, p. 73).

Segundo Kant, o erro categórico que constante cometeu foi o de confundir a ação pela qual alguém prejudica outro homem por ser verídico em uma declaração que não pode ser evitada, com aquela pela qual realiza uma injustiça a esse outro. Para o filósofo alemão é apenas por eventualidade que uma declaração verdadeira pode lesar outrem. Pois cada homem tem o dever e o direito de ser verídico nas declarações que não pode evitar, por mais que sua veracidade cause danos a ele ou a outros. Por conseguinte, aquele que foi verídico à pergunta do assassino, tomado de fúria, relativa à presença da pessoa odiada perseguida por ele em sua casa, "não faz com isso propriamente nenhum dano a quem é lesado, mas é o acaso que causa este dano. Porque neste caso o individuo não é absolutamente livre para escolher, porquanto a veracidade é um dever incondicionado." (KANT, 2013, p. 73). Para terminar, Kant afirma que:

Embora por uma certa mentira não faça com esta ação uma injustiça a ninguém, contudo atento em geral contra o princípio do direito, no que se refere a todas as declarações inevitavelmente necessárias (cometo uma injustiça formaliter, embora não materialiter), o que é ainda muito pior do que cometer uma injustiça contra um certo individuo, porque uma tal ação nem mesmo supõe sempre um princípio para ela no sujeito. (KANT, 2013, p. 74).

\section{Considerações finais}

Tratamos neste artigo, do problema central da nossa pesquisa, a saber, a questão da mentira. Kant a define como uma inverdade intencional que envolve questões tanto éticas como jurídicas, pois o ato de mentir além de tornar indigno quem o pratica ainda torna inútil a fonte do direito. Benjamim Constant criticou Kant por ter afirmado que a mentira, independente de qual seja, é inadmissível porque torna o homem indigno. Para Constant, um direito de mentir em determinados casos é legitimado, pois, segundo o filósofo, dizer a verdade só é, portanto, um dever em relação àqueles que têm direito à verdade. Sendo o dever aquilo que corresponde aos direitos de um outro, então, aonde não há direitos não há deveres. Kant refuta Constant ao afirmar que seu posicionamento sobre um 
suposto direito de mentir, em primeiro lugar; se trata de uma fórmula pouco clara, na medida em que a verdade não é um bem ao qual o direito possa ser outorgado a alguém, mas negado a um outro; em segundo lugar, e sobretudo, porque o dever de veracidade não faz nenhuma distinção entre pessoas em relação às quais se tem esse dever, ou em relação às quais também se pudesse isentar dele, isso porque é um dever incondicional, válido em todas as circunstâncias. Pois, a mentira, enquanto violação do dever ético, é um ato indigno, que merece desprezo.

Assim, podemos concluir que, para Kant, a questão da mentira é um problema moral, que envolve tanto a ética quanto o direito, onde não é possível um direito de mentir nem a sua legitimação. Pois, nenhuma inverdade intencional na manifestação dos pensamentos de alguém pode deixar de ser considerado como mentira, e tal ato sempre viola o direito de outrem, ao tornar inútil a fonte do direito, pois, sendo o princípio de veracidade um dever "que deve ser considerado a base de todos os deveres a serem fundados sobre um contrato, e a lei desses deveres, desde que se the permita a menor exceção, torna-se vacilante e inútil." (KANT, 2013, p. 74). Deste modo, a mentira por mais que seja boa intencionada nunca poderá ser aceita, pois, é um ato indigno, que merece desprezo.

\section{Referências bibliográficas}

ABBAGNANO, Nicolas. Dicionário de Filosofia. Martins Fontes. São Paulo. 1998

BARBOSA, Evandro. Direito e Moral em Kant.Dissertação: Mestrado em Filosofia, Faculdade de Filosofia e Ciências Humanas da Pontifícia Universidade Católica do Rio Grande do Sul, 2006.

COMTE, Sponville André. Dicionário filosófico. Martins Fontes. São Paulo, 2003.

FARIA, Maria do Carmo Bettencourt de. Direito e ética: Aristóteles, Hobbes, Kant. São Paulo: Paulus, 2007.

KANT, Immanuel. A Metafísica dos Costumes [1797]. Trad. bras. Edson Bini. Bauru: EDIPRO, 2008.

.Crítica da Razão Prática. Tradução baseada na edição original de 1788, com introdução e notas Valerio Rohden. - $3^{\circ}$. Ed. - São Paulo: Editora WMF Martins Fontes, 2011.

.Fundamentação da Metafísica dos Costumes. Tradução

de: Paulo Quintela. Textos Filosóficos. Lisboa: Edições 70, 2009.

.Fundamentação da Metafísica dos Costumes. Tradução

de: Guido Antônio de Almeida. São Paulo: Discurso Editorial: Barcelona, 2009.

.Textos Seletos. Tradução de: Emanuel Carneiro Leão.

Petrópolis: Vozes, 2013. 
HECK, José N. "A dupla legislação e a classificação dos deveres em Kant". In: Justiça e política: homenagem a Otfried Höffe. Oliveira e Souza (org.). Porto Alegre: EDIPUCRS, 2003.

HÖFFE, Otfried. Immanuel Kant. Tradução Christian Viktor Hamm, Valerio Rohden. - São Paulo: Martins Fontes, 2005.

PUENTE, Fernando Rey (org.). Os filósofos e a mentira. Belo Horizonte: Editora UFMG, 2002.

SALGADO, Joaquim Carlos. A idéia de Justiça em Kant: seu fundamento na liberdade e na igualdade. 2. ed. Belo Horizonte: Editora UFMG, 1995.

SILVA, André Luiz da. A relação entre ética e direito na filosofia de Immanuel Kant. Dissertação: Mestrado em Filosofia, Universidade Federal de Santa Catarina - UFSC. Florianópolis, 2011.

TERRA, Ricardo R. Kant e o direito. Rio de Janeiro: Jorge Zahar Ed., 2004. WOOD, A. Kant's Compatibilism. In: WOOD, Allen W. Self and Nature in Kant's Philosophy. London: Cornell University Press, 1984.

Contribuição dos autores:

Francisco Eliandro Souza do Nascimento e Jorge Luis Carneiro Lopes contribuíram com a discussão, problematização, revisão e redação do artigo. A versão final do texto foi aprovado por ambos os autores 